\title{
CAMINHOS PARA UNIVERSIDADE
}

Paths to University

Caminos a la universidad

Elton Batista Reis ${ }^{1}$, Euclides Pereira Marinho ${ }^{1}$, Cilicia Coelho Fragoso ${ }^{1}$ Amadeus Vieira Soares $^{2}$, Antônia Marcia Duarte Queiroz ${ }^{3}$

${ }^{1}$ Curso de Geografia, Universidade Federal do Tocantins, Araguaína, Brasil.

${ }^{2}$ Professor de Geografia, Diretoria Regional de Educação de Araguaína, Brasil

${ }^{3}$ Professora Adjunta, Curso de Geografia, universidade Federal do Tocantins, Araguaína, Brasil

\section{Artigo recebido em 10/04/2020 aprovado em 15/04/2020 publicado em 18/04/2020.}

\section{INTRODUÇÃO}

Partindo de observações feitas na escola percebemos que a grande maioria dos estudantes do $3^{\circ}$ do ensino médio no Colégio Estadual Jardim Paulista desconheciam o caminho de oportunidades que foi criado nos últimos anos, para que os estudantes de escola pública, e de baixa renda pudesse ter acesso ao ensino superior público. A grande maioria pensava que era inacessível o acesso a UFT. Partindo desse princípio elaboramos com muito cuidado o projeto Caminhos para a Universidade que tinha como objetivo central apresentar informações acerca das formas de acesso ao ensino superior público a estudantes da rede básica de ensino, a partir da Universidade Federal do Tocantins na Cidade de Araguaína - TO. E, expor aos estudantes através de palestra, os meios de ingresso a Universidade, além de estimulá-los a se inscrever no ENEM, Vestibulares e demais processos seletivos que são os meios mais conhecidos de acesso as instituições de ensino superior públicas.

Sendo assim o principal propósito é impulsionar o conhecimento dos mesmos sobre o ensino superior. Os objetivos possuem os DOI: http://dx.doi.org/10.20873/uftsupl2020-8895 seguintes pontos: Esclarecer dúvidas aos estudantes do Colégio Jardim Paulista sobre o acesso ao ensino superior público na cidade de Araguaína; Mostrar aos estudantes do $3^{\circ}$ ano as dependências físicas e administrativas da UFT/campus de Araguaína e, por último incentivar estudantes do ensino médio a continuidade de estudos. Sobretudo a importância da continuidade da sua formação no ensino superior.

\section{METODOLOGIAS E MATERIAIS}

Consistiu em uma primeira etapa, ofertar aos estudantes dos terceiros anos do ensino médio palestras sobre educação superior e o seu funcionamento, bem como, os cursos oferecidos na Universidade Federal do Tocantins Campus Araguaína.

Após as palestras os estudantes foram conduzidos ao laboratório de informática e foram auxiliados na realização das inscrições no Exame Nacional do Ensino médio, o qual é na atualidade a principal porta de acesso ao ensino superior. Ministramos a palestra tendo como ferramentas de apoio o uso de data show, computador em ambiente fechado na 
própria escola e, o laboratório de informática. Já na segunda etapa, previamente programada com o acompanhamento e sob responsabilidade da Direção escolar realizamos trabalho de campo conduzindo os estudantes do terceiro ano da escola-campo, Colégio Estadual Jardim Paulista escola, localizada afastada do centro da cidade, para uma visita guiada as instalações da UFT Campus Araguaína, com a colaboração dos colegiados e professores do campus Cimba, que realizaram exposições e diversos experimentos preparados nos respectivos laboratórios. Isso, para que os estudantes tivessem uma imersão na dinâmica da vida na universidade e conhecessem a infraestrutura da universidade, aguçando assim ainda mais o seu interesse para com os cursos.

A unidade escolar colaborou em todos os momentos das ações do projeto, no ambiente escolar, disponibilizando espaço para a realização das palestras, bem como acompanhando a todas as ações desenvolvidas pelo projeto, incluindo acompanhar os estudantes durante a visita de campo na UFT/ campus Araguaína.

\section{RESULTADOS E DISCUSSÃO}

O projeto Caminhos para a Universidade obteve resultados significativos, no tocante aos objetivos que foram traçados e sua execução. Durante as etapas a participação e contribuição dos estudantes foram marcantes. Para a maioria destes, a Universidade pública era algo fora da realidade. Esta afirmação inclusive foi levantada durante a palestra e, isso foi perceptível de se observar na primeira etapa que realizamos na escola. Um dos pontos que surpreenderam a todos nós foi ao falarmos sobre o programa nacional de assistência estudantil e os diversos auxílios destinados aos alunos de baixa renda, para que possam ter sua permanência garantida durante a graduação, além dos diversos programas de bolsa de iniciação científica desenvolvidos na IES em questão.

$\mathrm{Na}$ visita guiada as instalações do campus Araguaína da UFT, os estudantes puderem acompanhar diversos experimentos científicos nos laboratórios. Esta etapa teve resultados mais expressivos, pois os estudantes puderam observar a dinâmica do dia a dia e do funcionamento de uma instituição pública de ensino superior. E, ficaram encantados com os experimentos, com a infraestrutura e, com as histórias de superação que ao longo do percurso ia sendo contada por todos nós.

Consideramos que as etapas foram realizadas com sucesso e uma complementou a outra. De alguma forma contribui para estímulo desses jovens no que diz respeito aos diversos caminhos que a educação superior pública pode oferecer em sua formação.

\section{CONCLUSÃO}

Observamos que o projeto Caminhos para a Universidade possui um diferencial que é levar a universidade para dentro da escola e trazer a escola para conhecer a universidade, quando falamos em levar a universidade para dentro da escola estamos nos referindo ao diálogo olho no olho, com a principal clientela de uma instituição de ensino superior pública, que são os 
estudantes da escola básica pública. Esse dialogo com todos, através de palestras educativas que pode levar o maior número possível de informações sobre o ensino superior público e sua importância para o desenvolvimento da educação e do país.

O projeto foi tão bem aceito que diversas outras escolas entraram em contato solicitando realização da ação. A imersão no ambiente universitário combinou numa complementação entre a teoria realizada durante as palestras e evidenciou que cursar um curso superior disponível na universidade pode ser o melhor caminho para futuras oportunidades e a mesma está a disposição de todos nós.

Existe, hoje, a preocupação com a inserção social, pois na sociedade surgem formas de conscientização por órgãos de representação social e solidária que vislumbram mudanças efetivas na busca de ações de qualidade que atendam às questões sociais, e desenvolvam projetos que possibilitem diminuir as diferenças. Promover o desenvolvimento a comunidades carentes, nos níveis de capacitar a inserção ao trabalho e garantir melhoria na educação.

Neste sentido, almeja-se uma atuação da universidade junto à comunidade, através da extensão, que busca atuar junto às necessidades da população nas questões de desenvolvimento e formas de amenizar as disparidades sociais regionais.
A professora e coordenadora professora Dra Antonia Marcia do Duarte Queiroz pela oportunidade de poder construir um projeto como foi o caminho para universidade, em seguida gostaria de agradecer ao colégio Estadual Jardim Paulista especialmente ao professor preceptor Amadeus Vieira Soares pelo apoio total na realização do projeto, a Universidade Federal do Tocantins e a Capes.

Todos os autores declararam não haver qualquer potencial conflito de interesses referente a este artigo.

\section{REFERÊNCIAS}

BRASIL, Ministério da Educação. Base Nacional Comum Curricular. Disponível: http://basenacionalcomum.mec.gov.br/. Acessado em: 25 de setembro de 2019.

ENEM 2019 - Exame Nacional do Ensino Médio. INEP - Instituto Nacional de Estudos e Pesquisas.

Disponível: https://enem.inep.gov.br/ Acessado em: 25 de setembro de 2019.

SGUISSARDI, V. Reforma universitária no Brasil - 1995-2006: precária trajetória e incerto futuro. Campinas, Educ. \& Soc., v. 27, n. 96 - Especial, p. 1021-1056, out., 2006.

TRIGUEIRO, M. Durmeval, (1968). Expansão do ensino. Ensaios sobre educação e universidade. Organizadores Maria de Lourdes de Alburquerque Fávero, Jader de Medeiros Brito. Brasília: Instituto Nacional de Estudos e Pesquisas Educacionais Anísio Teixeira, 2006.

OLIVEIRA, J. F.; BITTAR, M. Ensino Superior noturno no Brasil: democratização do acesso, da permanência e da qualidade. In: Congresso IberoBrasileiro de Política e Administração da Educação, 1. Congresso Luso-Brasileiro De Política E Administração Da Educação, 6., Congresso do Fórum Português de Administração Educacional, 4.,.Portugal/Espanha, Anais... São Paulo: Anpae, 2010.

Plano de Desenvolvimento Institucional (PDI) 2016-2020. UFT. Disponível: https://ww2.uft.edu.br/pdi. Acessado em: 25 de setembro de 2019.

\section{AGRADECIMENTO}

